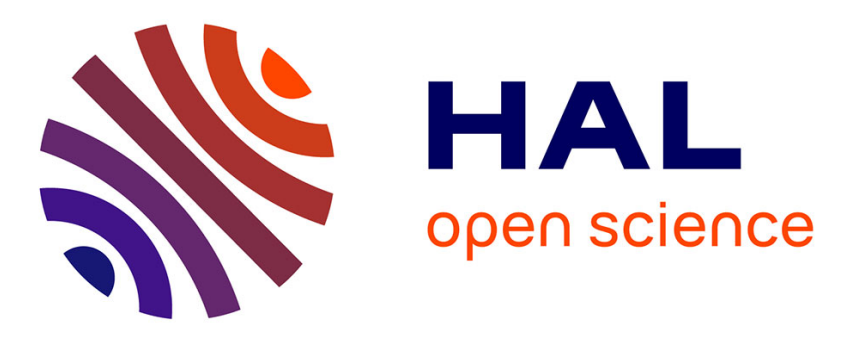

\title{
First description of nest-decoration behaviour in a wild sub-Antarctic shorebird
}

\author{
Samara Danel, Timothée Zidat, Annick Lucas, Dora Biro, Francesco \\ Bonadonna
}

\section{- To cite this version:}

Samara Danel, Timothée Zidat, Annick Lucas, Dora Biro, Francesco Bonadonna. First description of nest-decoration behaviour in a wild sub-Antarctic shorebird. Behavioural Processes, 2021, 188, pp.104408. 10.1016/j.beproc.2021.104408 . hal-03324982

\section{HAL Id: hal-03324982 \\ https://hal.science/hal-03324982}

Submitted on 24 Aug 2021

HAL is a multi-disciplinary open access archive for the deposit and dissemination of scientific research documents, whether they are published or not. The documents may come from teaching and research institutions in France or abroad, or from public or private research centers.
L'archive ouverte pluridisciplinaire HAL, est destinée au dépôt et à la diffusion de documents scientifiques de niveau recherche, publiés ou non, émanant des établissements d'enseignement et de recherche français ou étrangers, des laboratoires publics ou privés. 


\section{First description of nest-decoration behaviour in a wild sub-Antarctic 3 shorebird}

\section{Samara Danel a, ${ }^{\star}$, Timoth 'ee Zidat b, Annick Lucas c, Dora Biro a,1, Francesco Bonadonna c,1}

a Department of Zoology, University of Oxford, Oxford, OX1 3PS, UK

b Cardiff University, School of Bioscience, Museum Avenue, Cardiff, Wales, CF10 3AX, UK c CEFE UMR 5175, CNRS - University of Montpellier - Paul-Val'ery Montpellier University EPHE, Montpellier, Cedex 5, France

5 A wide range of animal species accumulate objects in, on, and/or around structures they build.

6 Sometimes, these accumulations are purely incidental, while in other cases the materials are

7 deliberately displayed to serve signalling purposes (extended phenotype signals). In this pilot

8 study, we employed systematic in situ observations and camera trapping to describe for the

9 first time that both sexes of a territorial shorebird, the black-faced sheathbill (Chionis minor

10 ssp minor) collect, carry, and arrange colourful marine shells and dried twigs within and

11 around their nest cavity. Our observations expand the taxonomic breadth of avian extended

12 phenotype signals, by showing that at least one species within a largely understudied group

13 i.e., Aequorlitornithes, exhibits nest-decoration behaviour. Multiple manipulative

14 experiments are needed to explore further the signalling function of these

15 decorations, which opens new exciting avenues for animal communication and

16 cognition research.

18 Keywords: animal communication - Charadrius $\cdot$ extended phenotype $\cdot$ nest decoration · 19 non-bodily ornament $\cdot$ signal 


\section{Introduction}

25 From the honeybee waggle dance to the dazzling mating display of cuttlefish, all live animals

26 possess the capacity to convey to others information that is crucial in various biological contexts (Bradbury and Vehrencamp 2011). While numerous species use bodily traits or behavioural displays to communicate, signals can also be expressed externally by animals as an extension of their phenotype (Dawkins, 2016). These 'extended phenotype signals' originate from the manipulative action or construction behaviour of the signaller and have the ability to provide information efficiently even in the signaller's absence (Schaedelin and Taborsky 2009). Recently, extended phenotype signals have received considerable attention in evolutionary and behavioural research as they represent excellent opportunities to study animal communication, and, contrary to bodily traits, are particularly well suited to experimental manipulations (Coleman et al. 2004, Jordan et al. 2016, Madden 2002, Magalhaes et al. 2013, Schaedelin and Taborsky 2009). For instance, a wide range of animal taxa use purely ornamental extended phenotype signals, resulting in the collection of decorative materials (reviewed in Schaedelin and Taborsky 2009). Those materials can be easily experimentally manipulated and thus offer elegant, relevant models for elucidating how they have evolved, what signalling function they serve, and how flexible individuals are in their deployment (Hansell 2000, Keagy et al. 2009, Sergio et al. 2011).

This latter behaviour i.e., the gathering of objects as decorations, has been particularly well described in birds, probably due to high observation effort (Amundsen 2003), ease of observation (Shumaker et al. 2011), and intricate nest-building abilities (Hansell 2000). In most cases, objects are associated with the building of nests or with the manipulative actions involved in nest construction (Borgia, 1986). Such decorations can originate from various types of inorganic (e.g. glass, small stones: Borgia 1995), vegetal (e.g. berries: Gilliard 1969, Forshaw and Cooper 1977, flowers: Borgia 1986), animal (e.g. animal fur: Pruett-Jones and 
Pruett-Jones 1988, feathers: Veiga and Polo 2005), or human artefact materials (e.g. toothbrush: Velenga 1970, foil: Jagiello et al. 2018). The diversity of these decorations and their taxonomically widespread use throughout the class Aves has fuelled the debate over their function for decades (Schuetz 2005).

Probably the most famous examples of avian extended phenotype signals are found in the Ptilonorynchidae family (Passeriformes), where males of 15 species build structures - bowers - that are often elaborately adorned to attract females during the breeding season (Borgia 1986, Hansell 2000, Doerr and Endler 2015, Endler et al. 2006, Endler et al. 2010, Endler 2012, Kelley and Endler 2012, Endler et al. 2014). In some bowerbirds, decorations coupled with structure building capacity may be associated with a larger brain compared to other related and unrelated non-bower building bird species (Madden 2001), and are hypothesized to be subject to cultural transmission (Madden 2008). Lately, the study of nest decorations has been particularly flourishing and has revealed other nonmutually exclusive functions (e.g. indicators of viability, territory quality, and conflict dominance of the signaller, Sergio et al. 2011, Canal et al. 2016) and factors affecting its expression (e.g. breeding density, Rubalcaba et al. 2017).

So far, only a few bird species - mainly Passeriformes - have been the object of experimental investigations (Schuetz 2005, Sergio et al. 2011, Figure 1). For a better understanding of the factors that drove the evolution of this behaviour, more effort is necessary in exploring nest-decoration activity in a larger range of species (Delhey et al. 2011, Sanz and García-Navas 2011). García-Navas et al. (2015) working on rock sparrows (Petronia petronia) have suggested two major signalling functions of nest decorations in birds: signalling individual and parental quality or advertising social status to other conspecifics. The fact that birds as distantly related as chinstrap penguins (Fargallo et al. 2001) and blue tits (Sanz and García-Navas 2011) might use decorations as a post-mating 
sexual display, or that objects deployed by raptors (Sergio et al. 2011) and owls (Penteriani and Delgado 2008) act as reliable threats to conspecifics, lead us to assume that nest decoration is the result of convergent evolution (Delhey et al. 2017). As such, reports on nest decoration in taxonomically distinct species can bring immense opportunities to assess, through comparative evaluation, what socioecological features may have driven the emergence this behaviour.

$<$ Insert Figure 1 about here $>$

The purpose of the present paper is to contribute to such a broad comparative endeavour, by describing nest-decoration behaviour in the black-faced sheathbill (Chionis minor ssp minor, closely related to Pluvianellidae, Charadriiformes, Winkler et al. 2020), a small terrestrial shorebird, which inhabits coastal regions of the Subantarctic Kerguelen Islands (Bried and Jouventin 1998, Burger and Kirwan 2020). In these rigorous environments characterized by inclement weathers and high predation levels, sheathbills are the only common land-based birds. To survive in these islands, they adapt their foraging to any form of animal matter and are highly opportunistic (Burger 1979, Blankley 1981, Winkler et al. 2020). They are scavengers, predators, and kleptoparasites, and their diet includes a large variety of food types e.g., algae, invertebrates, carrion, seabirds' faeces, feather-shafts, eggs, and chicks (Burger 1981). Black-faced sheathbills are monogamous and both sexes vigorously defend their feeding and breeding territories against intruders through ritualized display calls (i.e. the common 'Bob-call') and threat postures (Burger 1979, Burger 1980, Verheyden 1988, Bried and Jouventin 1996, Jouventin et al. 1996). The nest consists of a simple cup hidden from view within a natural cavity such as a crevice, small cave, or more occasionally a petrel burrow (Winkler et al. 2020). In the Kerguelen archipelago, we noted that many nests open onto areas covered with conspicuous purple mussel shells. Through systematic observations, we documented this previously undescribed behaviour and 
99 investigated the possibility that these objects located in and around the nest were not 100 incidental accumulations of debris and/or prey remains, but rather served as decorative 101 materials. If so, we expected the birds to engage in the collection of materials and in specific 102 manipulative behaviours targeted at them at the nest area. As incubation is undertaken by both 103 sexes in this species (Burger and Kirwan 2020), we also examined whether only one or both 104 individuals of the breeding pair engaged in these behaviours.

\section{Material and Methods}

106 Study site and subjects

107 Observations took place at Ile Verte $\left(49^{\circ} 30^{\prime} 23^{\prime}\right.$ ' $\left.\mathrm{S}, 70^{\circ} 02^{\prime} 40^{\prime \prime} \mathrm{E}-1.5 \mathrm{~km}^{2}\right)$, an island situated 108 within the Morbihan Gulf, Kerguelen archipelago $\left(48^{\circ} 28^{\prime}-50^{\circ} \mathrm{S}, 68^{\circ} 28^{\prime}-70^{\circ} 35^{\prime} \mathrm{E}\right)$, during the 109 Dec 2019 - Jan 2020 breeding season. At this location, black-faced sheathbills defend and 110 remain in one territory all year (Burger and Kirwan 2020), thus facilitating observations. 111 Three nest-cavities were identified: Nest 1 belonged to breeding pair A1/A2, and Nest 2 \& 112 Nest 3 to breeding pair B1/B2. Areas that contained objects consisted of two terrace areas: 113 one below (terrace area 1) and one above (terrace area 2) the nest cavity for Nest 1 and Nest 3 114 (see example of Nest 1 in Figure 2), and one circular area in front of the nest cavity for Nest 1152 (Figure 3).

117 Daily observations confirmed that Nest 2 was still maintained but, probably due to the high 118 nest cavity visibility and ease of access that attracted nearby avian predators (e.g., brown 119 skuas Catharacta antarctica ssp lonnbergi), the pair selected another cavity to incubate the 120 eggs, i.e. Nest 3, which was located about 6 meters away from Nest 2.

121 Set up and materials

122 Data collection consisted of daily observations supplemented by photographs and video 123 recordings (camera traps). Direct observations, which did not exceed 15 min each, were 
124 conducted every two days between 8 a.m. and 11 a.m. through Dec-Jan 2020. From $12^{\text {th }}$ Jan

125 to $14^{\text {th }}$ Jan 2020 , one camera trap with motion detection recording (RECONYX® HL2X

126 HyperFire 2) was set up within each territory in order to collect data on the type, manipulation

127 time, origin, and dropping zone of objects. From $27^{\text {th }}$ Jan to $29^{\text {th }}$ Jan 2020 , one camera trap

128 was also used to determine whether both mates contributed simultaneously to collection. We

129 used daily observations and photographs to minimise disturbance to the birds during the

130 breeding period (Jouventin et al. 1996).

131 Scoring and analysis

132 Photographs. For each photograph, we quantified (i) the type of objects (from complete and 133 fragment materials), (ii) their position (coloured topside up/down), and (iii) their number and

134 location in their respective areas (circular: Nest 2, and terrace areas: Nest $1 \& 3$ ).

135 Video-recordings. We examined: (iv) which object the bird was manipulating (objects newly 136 collected or already present in the display areas), (v) the total manipulation time (from the 137 time the bird first picks up the object, or first appears in view carrying it, until it drops it on 138 the terrace areas or outside the field of the camera), (vi) the origin of the object (inside the 139 nest, terrace areas, outside the filming zone), and where it was dropped off (inside/outside the 140 nest cavity, high/low terrace area). We also noted whether both mates contributed 141 simultaneously to collection.

142 Results

143 Nest-decoration behaviours.

144 Photographs.

145 (i) Type. Marine mussels (ribbed mussel Aulacomya ater and blue mussel Mytilus 146 desolationis) and limpets (Nacella kerguelenensis) composed the pattern of objects (Figure $1474)$. 
(ii) Position. Most shells, irrespective of the species, were placed with their shiny coloured topsides uppermost: $98 \%$ across the two terrace areas at Nest $1,98 \%$ in the circular area at Nest 2, and $92 \%$ across the two terrace areas in Nest 3.

(iii) Number and location. At Nest 1, terrace area 1 (below the nest cavity entrance) was composed of $96 \%$ ribbed mussels, $3 \%$ blue mussels, and 1\% limpets. Terrace area 2 (above the entrance) contained 92\% ribbed mussels, 6\% blue mussels, and 2\% limpets (Table 1).

154 Across the two terrace areas, Nest 1 thus had 95\% ribbed mussels, $4 \%$ blue mussels, and 1\% 155 limpets. At Nest 2 the main circular area contained 98\% ribbed mussels, $1.80 \%$ blue mussels, and $0.20 \%$ limpets. At Nest 3, terrace area 1 was composed of $96 \%$ ribbed mussels, $2 \%$ blue mussels, and $2 \%$ of limpets, while terrace area 2 contained $95 \%$ ribbed mussels and 5\% 158 limpets. Across the two terrace areas, Nest 3 thus had $96 \%$ ribbed mussels, $1 \%$ blue mussels, 159 and $3 \%$ limpets.

(iv) Type. In a total of 299 video recordings (recording time for each video: $30 \mathrm{~s}$ ), $42 \%$ of 163 the objects manipulated were shells (ribbed mussels: 16\%, unidentified mussels: 11\%, and 164 limpets: 15\%), 5\% were unknown objects, and 53\% were dry Scenecio vulgaris twigs.

(v) Manipulation time. Mean $\pm \mathrm{SD}$ manipulation time was $5 \pm 5 \mathrm{~s}(\mathrm{n}=2$, range 1-20 s) for ribbed mussels, $6 \pm 5(\mathrm{n}=2$, range 1-12 s) for unidentified mussels, $7 \pm 5(\mathrm{n}=2$, range 2-20

$167 \mathrm{~s})$ for limpets, $7 \pm 9(\mathrm{n}=2$, range $1-30 \mathrm{~s})$ for twigs, and $2 \pm 2(\mathrm{n}=2$, range 1-6 s) for unknown 168 objects.

169 (vi) Origin and dropping zones. We never observed birds carrying objects inside the nest cavity, however sheathbills manipulated objects already within the nest cavity in $12 \%$ of

171 observations. When objects were moved between areas, the direction of movement most often 172 included bringing objects from beyond the nest area (from outside the filming zone) to terrace 
173

174

175

176

177

178

179

180

183

areas (the camera trap was only able to cover terrace area 2, 19\% of observations), but we also observed carrying from the nest cavity to terrace area $2(1 \%)$, and from the terrace area to outside the nest area (3\%). The manipulation and displacement of objects within the same area (terrace area 2) were noted in $33 \%$ of observations. Finally, in $32 \%$ of observations, birds arrived with an object from outside the nest area but did not deposit it; i.e. they eventually left the nest area holding the same object.

\section{Contribution to collection.}

Video-recordings (27th Jan - 29 th Jan 2020)

Neither breeding pair ever manipulated and placed objects simultaneously. However, when an individual contributed to collection and, after some time, took over incubation from the partner, the previously incubating bird also moved and placed objects within the filming zone during its off-duty (object manipulations that occurred during pre- and post-switching event: twice on Jan $27^{\text {th }}$, once on Jan $28^{\text {th }}$, and once on Jan $29^{\text {th }}$ ). We also observed both partners engaging in object manipulation before and after switching incubation 4 times on Jan $13^{\text {th }}$.

\section{Discussion}

We document for the first time aspects of object transportation, handling, and arranging in the vicinity of the nest, in Aequorlitornithes. Similar nest-decoration behaviour has been reported in relatively distantly related species with different ecological backgrounds, such as kites and bowerbirds (e.g. Sergio et al. 2011, Borgia 1986; respectively). We suggest that sheathbills offer an interesting comparison to investigate which factors drove the evolution of this behaviour among birds.

Most of the material collected was composed of ribbed mussels, followed by, to a lesser extent, blue mussels and limpets. All these materials are highly abundant in the sheathbills' environment. Video recordings confirmed birds' direct handling of the shells seen in the photographs and revealed another type of object scavenged from the environment: dry 
198 Scenecio vulgaris dried twigs, also commonly collected. The volatile property of twigs within

199 the windy Kerguelen archipelago might explain why they were missing from the photographs.

200 Although birds' preference for shells has been ascribed to a need for calcium-rich food items

201 for successful breeding in some bird species (e.g. small passerines Bureš and Weidinger 202 2001), the sheer quantity of empty mussels within and outside the nest cavity makes this 203 explanation unlikely. Importantly, all objects were predominantly placed with their topsides 204 uppermost on specific platforms, and their origin and displacements within the nest area 205 seemed to indicate a selection of the objects arranged on the terrace areas.

The fact that sheathbills select, carry, and arrange empty shells on nest areas align well with our hypothesis that the configuration of objects is not purely incidental. Materials placed 208 by sheathbills seem rather to be decorations independent of strict survival or reproductive 209 requirements (i.e. not collected in the context of feeding or to serve as insulation, for example). We therefore suggest, for the first time, that the decorations may have a signalling 211 function in sheathbills (Veiga and Polo 2005, Canal et al. 2016).

212 Similarly to sheathbills, a number of species use materials that they place outside the nest 213 without any apparent purpose in incubation or nestling rearing (e.g. male yellow-breasted 214 bowerbirds Chlamydera lauterbachi, Gilliard 1969, Dunning 1993, female spotless starlings 215 Sturnus unicolor, Polo et al. 2004, Polo and Veiga 2006, male blue tits Cyanistes caeruleus, 216 Sanz and García-Navas 2011, and mated pairs of black wheatears Oenanthe leucura, Moreno 217 et al. 1994). Three non-mutually exclusive explanations may be suggested in regard to what 218 information sheathbills convey with these objects: mate attraction before pair formation (e.g. 219 Endler et al. 2005), post-mating sexual selection (e.g. mate fidelity and investment in 220 reproduction, Polo et al. 2004), and territory occupancy (e.g. Sergio et al. 2011).

221 On Verte Island, sheathbills breed on shores free of penguin colonies and forage mainly on 222 algae, crustaceans, and molluscs (Jouventin et al. 1996). The number of objects displayed at 
nesting sites, i.e. the quantity of empty mussels sheathbills are able to collect, may represent

224 reproductive traits indicative of genetic or parental quality, such as feeding effort and foraging 225 ability (Sanz and García-Navas 2011). In polygynous species such as bowerbirds, the number 226 and quality of nest decorations (i.e. blue feathers) reinforce the attractiveness of the males 227 (Haruyama et al. 2013). For instance, Borgia (1985) observed fewer copulations of satin 228 bowerbirds (Ptilonorhynchus violaceus) when ornaments were removed (experimental group) 229 than when no manipulation occurred (control group). Yet, selection occurs solely prior to 230 pairing in bowerbirds, and only one sex - the male - invests in nest construction and 231 associated ornamental addition. In sheathbills, however, both partners contribute to breeding 232 and we found that they start to engage in decoration collection approximately two months 233 after they first occupy their territory in October (i.e. laying period, Burger and Kirwan 2020).

234 Although we cannot rule out the possibility that some form of mate attraction occurs before 235 pairing, nest-decoration behaviour may share other nonmutually exclusive functions.

236 Signalling through nest decoration after pairing may be driven by post-mating forms of 237 sexual selection, for instance through partners' differential allocation of investment of mates 238 in the clutch (Moreno et al. 1994). Differential allocation after pair bond formation has been 239 shown in several avian species where both sexes contribute to nest decoration and/or nest 240 construction (e.g. black wheatears, Moreno et al. 1994, blue tits Cyanistes caeruleus, Sanz 241 and García-Navas 2011, but see Tomás et al. 2006, Lambrechts et al. 2012, magpies Pica 242 pica, Soler et al. 2001, buff-breasted wrens Cantorchilus leucotis, Gill and Stutchbury 2005). 243 Longer incubation shifts have been observed in some male sheathbills (mean incubation shift 244 length for males and females = 172 minutes and 90 minutes, respectively; Burger and Kirwan 245 2020). Females may benefit from increased efforts expanded by males in incubation duration. 246 In turn, male sheathbills that contribute more to nest decoration may prompt a heavier 247 investment in offspring by females. For instance, as hatching is asynchronous in this species 
248 (i.e. eggs in a single clutch hatch sequentially, Burger and Kirwan 2020), females may decide

249 to incubate earlier by allowing greater intervals between egg-laying, thus facilitating brood 250 reduction (Soler et al. 2001).

251 Another non-mutually exclusive explanation to a sexual component is the use of nest 252 decorations in the context of resource defence (Sergio et al. 2001). Similarly to the sheathbill, 253 on return from its migration, the black kite (Milvus migrans) occupies a breeding territory that 254 is highly defended by both individuals within the pair (Bustamante and Hiraldo 1993). 255 Beyond contributing together to nest building, the partners also decorate the nest with various 256 materials that they arrange in a conspicuous fashion (Mazumdar et al. 2017). This latter 257 feature, i.e. conspicuousness, represents a reliable threat indicating viability, territory quality, 258 and conflict dominance of the signaller (Sergio et al. 2011), but also enhances nest visibility 259 to aerial receivers (Canal et al. 2016). Raptors such as black kites are fierce birds (Orta et al. 260 2020), so natural selection (in the form of, for example, nest predation) is unlikely to have 261 significantly constrained signalling through nest decoration and construction (Moreno et al. 262 2012). Although the accumulation of objects around the nest is conspicuous in sheathbills, 263 nest-decoration activity and high visibility may attract the attention of predators such as skuas 264 and other sheathbills (Burger and Bonan 2020). If this resource-defence hypothesis is true, a trade-off may therefore exist between elaborate nest decoration to warn off competitors and

266 the need for concealment of the nest from predators (the latter may be modulated by choosing 267 less conspicuous locations during nest-site selection). Best quality mates exhibiting numerous 268 decorations may be more able to cope with (the potential cost of) facing potential predators 269 and conspecific intruders, echoing the handicap principle (Zahavi 1975).

270 Overall, our findings lead us to suggest that sheathbills' nest decoration acts as an extended 271 phenotype signal that has evolved due to sexual selection, potentially through differential 272 allocation of investment by partners. Our results also support the nonmutually exclusive 
273 hypothesis of territory defence, potentially traded off against natural selection in the form of

274 predation risk. It is worth noting that nest decoration has not been reported in sheathbills that

275 breed and feed within seabird colonies (e.g. crested penguins or Kerguelen cormorants

276 Phalucrocorux atriceps verrucosus, Weimerskirch et al. 1989), which paves the way to future

277 intraspecific comparative studies in order to understand the ecological circumstances

278 favouring the emergence of nest decoration in this peculiar species. We hypothesize that

279 differences attributable to contrasting ecologies and population dynamics (e.g. foraging for

280 mussels in the intertidal zone, predictable and more competitive environment for sheathbills

281 living in localities free of penguins) may play a role in the emergence of nest-decoration 282 behaviour.

283 While our study provides clear evidence of nest-decoration behaviour in black-faced 284 sheathbills, further manipulative experiments, inspired by well-established studies in other 285 species, will be necessary to address more nuanced questions about the behaviour. These 286 should assess whether the signal is reliable in the context of territory defence and sexual 287 competition (e.g. Madden 2002, Sergio et al. 2011), seek correlations between the quantity (or 288 quality) of nest decoration and reproductive success/offspring fitness, and learn more about 289 the decoration process itself (e.g. Borgia, 1985, Borgia et al., 1987, Vellenga, 1986, Maxwell, 290 1999).

291 In conclusion, in this observational study we suggest that the materials placed by 292 sheathbills in and around the nest cavity serve a signalling function. This discovery extends 293 the known phylogenetic and geographic spread of this rare behaviour among birds, and 294 supports the hypothesis that nest decoration in sheathbills may represent a case of convergent 295 evolution. Manipulative experiments, with marked individuals of known age, sex, and body 296 condition, need to be conducted before firm conclusions can be drawn about the precise 297 function of these decorations. Despite its broader appeal, so far nest decoration has been 
298 studied in a small range of avian orders, and more particularly in passerine species where

299 decorations are deployed by one sex solely for mate attraction and courtship (Sergio et al., 300 2011). The black-faced sheathbill may represent a new model species for investigating the 301 function and evolution of ornamental extended phenotype signals - as well as the cognition 302 underpinning it - thus opening up new promising avenues for future research.

\section{Declarations}

304 Funding - The research was funded by I.P.E.V. grants (to FB, ETHOTAAF 354) and by 305 the Fyssen Foundation (to TZ and SD).

306 Conflict of interest - the authors do not have any conflict of interest to declare.

\section{References}

308 Amundsen, T. 2003. Fishes as models in studies of sexual selection and parental care. J. Fish Biol. 63: 17-52.

Blankley. W.O. 1981. Marine food of Kelp Gulls. Lesser Sheathbills and Imperial Cormorants at Marion Island (Subantarctic). Cormorant 9: 77-84.

Burger, A.E. 1979. Breeding biology, moult and survival of Lesser Sheathbills Chionis minor at Marion Island. Ardea 67: 1-14.

314 Bolles, F. 1890. Snake skins in the nests of Myiarchus crinitus. Auk 7: 288-288.

315 Borgia, G. 1985. Bower quality, number of decorations and mating success of male satin bowerbirds (Ptilonorhynchus violaceus): an experimental analysis. Anim. Behav. 33: 266-271.

318 Borgia, G. 1986. Sexual selection in bowerbirds. Sci. Am. 254: 92-101.

319 Borgia, G. 1995. Threat reduction as a cause of differences in bower architecture, bower decoration and male display in two closely-related bowerbirds Chlamydera nuchalis and C. maculata. Emu 95: 1-12. 
Borgia, G., Kaatz, I. M. and Condit, R. 1987. Flower choice and bower decoration in the satin bowerbird Ptilonorhynchus violaceus: a test of hypotheses for the evolution of male display. Anim. Behav. 35: 1129-1139.

Bradbury, J. W., Vehrencamp, S. L. 2011. Principles of animal communication. Sunderland: Sinauer Associate.

Bried, J. and Jouventin, P. (1998). Why do Lesser Sheathbills Chionis minor switch territory? J. Avian Biol. 29: 257-265.

Burger, A. E. 1979. Breeding biology, moult and survival of Lesser Sheathbills Chionis minor at Marion Island. Ardea 67: 39-43.

Burger, A. E. 1980. An analysis of the displays of the Lesser Sheathbill Chionis minor. Z. Tierpsychol. 52: 38-396.

Burger, A. E. 1981. Time budgets, energy needs and kleptoparasitism in breeding Lesser Sheathbills (Chionis minor). Condor 83: 106-112.

Burger, A.E. and Kirwan, G.M. 2020. Black-faced Sheathbill (Chionis minor). In: del Hoyo, J., Elliott, A., Sargatal, J., Christie, D.A. \& de Juana, E. (eds.), Handbook of the Birds of the World Alive. Lynx Edicions, Barcelona.

Bureš, S. and Weidinger, K. 2001. Do pipits use experimentally supplemented rich sources of calcium more often in an acidified area? J. Avian Biol. 32: 194-198.

Bustamante, J. and Hiraldo, F. 1993. The function of aggressive chases by breeding Black and Red Kites Milvus migrans and M. milvus during the post-fledging dependence period. Ibis 135: 139-147.

Canal, D., Mulero-Pazmany, M., Negro, J. J. and Sergio, F. 2016. Decoration increases the conspicuousness of raptor nests. PloS one 11: e0157440.

Coleman, S. W., Patricelli, G. L., Borgia, G. 2004. Variable female preferences drive complex male displays. Nature 428: 742-745. 
347 Dawkins, R. 2016. The extended phenotype: The long reach of the gene. Oxford, Oxford $348 \quad$ University Press.

349 Delhey, K., Carrizo, M., Mahler, B. and Peters, A. 2017. Complex nest decorations of a small 350 brown bird in the Pampas. Natural History Notes 406-407.

351 Doerr, N. R. and Endler, J. A. 2015. Illusions vary because of the types of decorations at bowers, not male skill at arranging them, in great bowerbirds. Anim. Behav. 99: 73-82.

353 Endler, J. A. 2012. Bowerbirds, art and aesthetics: Are bowerbirds artists and do they have an aesthetic sense? Commun. Integr. Biol. 5: 281-283.

355 Endler, J. A., Westcott, D. A., Madden, J. R., and Robson, T. 2005. Animal visual systems and the evolution of colour patterns: sensory processing illuminates signal evolution. Evolution 59: 1795-1818.

Endler, J. A., Endler, L. C. and Doerr, N. R. 2010. Great bowerbirds create theaters with forced perspective when seen by their audience. Curr. Biol. 20: 1679-1684.

360 Endler, J. A., Gaburro, J. and Kelley, L. A. 2014. Visual effects in great bowerbird sexual displays and their implications for signal design. P. Roy. Soc. B-Biol. Sci. 281: 20140235.

Endler, J. A. and Day, L. B. 2006. Ornament colour selection, visual contrast and the shape of colour preference functions in great bowerbirds, Chlamydera nuchalis. Anim. Behav. 72: 1405-1416.

Forshaw, J. M. and Cooper, W. T. 1977. The birds of paradise and bower birds. Collins, Boston.

Fargallo, J. A., De León, A. and Potti, J. 2001. Nest-maintenance effort and health status in chinstrap penguins, Pygoscelis antarctica: the functional significance of stoneprovisioning behaviour. Behav. Ecol. Sociobiol. 50: 141-150. 
371 García-Lo pez de Hierro, L., Moleo n, M. and Ryan, P. G. 2013. Is carrying feathers a sexually selected trait in house sparrows? Ethology 119: 1-13.

373 García-Navas, V., Valera, F. and Griggio, M. 2015. Nest decorations: an 'extended'female badge of status? Anim. Behav. 99: 95-107.

375

Gilliard, E. T. 1969. Birds of paradise and bower birds. George Weidenfeld \& Nicholson.

Hansell, M. 2000. Bird nests and construction behaviour. Cambridge University Press.

Haruyama, N., Yamaguchi, N., Eguchi, K. and Noske, R. A. 2013. Experimental evidence of local variation in the colour preferences of Great Bowerbirds for bower decorations. Emu 113: $367-373$.

Jagiello, Z. A., Dylewski, Ł., Winiarska, D., Zolnierowicz, K. M. and Tobolka, M. 2018. Factors determining the occurrence of anthropogenic materials in nests of the white stork Ciconia ciconia. Environ. Sci. Pollut. Research 25: 14726-14733.

Jouventin, P., Bried, J. and Ausilio, E. 1996. Life-history variations of the Lesser Sheathbill Chionis minor in contrasting habitats. Ibis 138: 732-741.

Jordan, L. A., Maguire, S. M., Hofmann, H. A., Kohda, M. 2016 The social and ecological costs of an 'over-extended' phenotype. Proc. R. Soc. B 283: 20152359.

Keagy, J., Savard, J. F., Borgia, G. 2009. Male satin bowerbird problem-solving ability predicts mating success. Anim. Behav. 78: 809-817.

Kelley, L. A. and Endler, J. A. 2012. Illusions promote mating success in great bowerbirds. Science 335: 335-338.

Lambrechts, M. M., Aimé, C., Midamegbe, A., Galan, M. J., Perret, P., Grégoire, A., \& Doutrelant, C. 2012. Nest size and breeding success in first and replacement clutches: an experimental study in Blue Tits Cyanistes caeruleus. J. Ornithol. 153: 173-179.

Madden, J. 2001. Sex, bowers and brains. P. Roy. Soc. B-Biol. Sci. 268: 833-838. 
395 Madden, J. R. 2002. Bower decorations attract females but provoke other male spotted bowerbirds: bower owners resolve this trade-off. P. Roy. Soc. B-Biol. Sci. 269: 13471351.

Madden, J. R. 2008. Do bowerbirds exhibit cultures? Anim. Cogn. 11: 1-12.

Magalhaes, I. S., Croft, G. E., Joyce, D. A. 2013. Altering an extended phenotype reduces intraspecific male aggression and can maintain diversity in cichlid fish. PeerJ 1: e209

Maxwell, P. S. 1999. Learning in immature male satin bowerbirds (Ptilonorhynchus violaceus) (Doctoral dissertation, BSc Dissertation, University of Queensland, Brisbane).

Mazumdar, S., Ghose, D., \& Saha, G. K. 2017. Nests of Black Kite (Milvus migrans govinda) in Urban Landscape of Kolkata, India. Proceedings of the Zoological Society (Vol. 70, No. 2, pp. 201-205). Springer, India.

Moreno, J. 2012. Avian nests and nest-building as signals. Avian Biol. Res. 5: 238-251.

Moreno, J., Soler, M., Møller, A. P. and Linden, M. 1994. The function of stone carrying in the black wheatear, Oenanthe leucura. Anim. Behav. 47: 1297-1309.

Orta, J., Marks, J. S., Garcia, E. F. J. and Kirwan, G. M. 2020. Black Kite (Milvus migrans). In: del Hoyo, J., Elliott, A., Sargatal, J., Christie, D. A. and de Juana, E. (eds.). Handbook of the Birds of the World Alive. Lynx Edicions, Barcelona.

Penteriani, V. and Delgado, M. M. 2008. Owls may use faeces and prey feathers to signal

414 Polo, V., Veiga, J. P., Cordero, P. J., Viñuela, J. and Monaghan, P. 2004. Female starlings adjust primary sex ratio in response to aromatic plants in the nest. P. Roy. Soc. BBiol. Sci. 271, 1929-1933.

417 Polo, V. and Veiga, J. P. 2006. Nest ornamentation by female spotless starlings in response to a male display: an experimental study. J Animal Ecol 75: 942-947. 
419 Pruett-Jones, S. G. and Pruett-Jones, M. A. 1988. The use of court objects by Lawes' parotia. Condor 90: 538-545.

421 Prum, R. O., Berv, J. S., Dornburg, A., Field, D. J., Townsend, J. P., Lemmon, E. M. and Lemmon, A. R. 2015. A comprehensive phylogeny of birds (Aves) using targeted nextgeneration DNA sequencing. Nature 526: 569-573.

Rubalcaba, J. G., Fuentes, D., Veiga, J. P. and Polo, V. 2017. Nest decoration as social signals by males and females: greenery and feathers in starling colonies. Behav. Ecol. 28: 13691375.

Sanz, J. J. and García-Navas, V. 2011. Nest ornamentation in blue tits: is feather carrying ability a male status signal? Behav. Ecol. 22: 240-247.

Schaedelin, F. C. and Taborsky, M. 2009. Extended phenotypes as signals. Biol. Rev. 84: 293-313.

Schuetz, J. G. 2005. Common waxbills use carnivore scat to reduce the risk of nest predation. Behav. Ecol. 16: 133-137.

433 Sergio, F., Blas, J., Blanco, G., Tanferna, A., López, L., Lemus, J. A. and Hiraldo, F. 2011. Raptor nest decorations are a reliable threat against conspecifics. Science 331: 327-330.

Shumaker, R. W., Walkup, K. R. and Beck, B. B. 2011. Animal tool behavior: the use and manufacture of tools by animals. JHU Press.

437 Smith, M. D. and Conway, C. J. 2007. Use of mammal manure by nesting burrowing owls: a test of four functional hypotheses. Anim. Behav. 73: 65-73.

439 Soler, M., Soler, J. J., Møller, A. P., Moreno, J. and Lindén, M. 1996. The functional significance of sexual display: stone carrying in the black wheatear. Anim. Behav.51,

442 Soler, J. J., Neve, L. D., Martínez, J. G. and Soler, M. 2001. Nest size affects clutch size and the start of incubation in magpies: an experimental study. Behav. Ecol. 12: 301-307. 
444 Tomás, G., Merino, S., Moreno, J., Sanz, J. J., Morales, J. and García-Fraile, S. 2006. Nest 445 weight and female health in the Blue Tit (Cyanistes caeruleus). Auk 123: 1013-1021.

446 Trnka, A. and Prokop, P. 2011. The use and function of snake skins in the nests of great reed $447 \quad$ warblers Acrocephalus arundinaceus. Ibis 153: 627-630.

448 Veiga, J. P. and Polo, V. 2005. Feathers at nests are potential female signals in the spotless $449 \quad$ starling. Biol. Lett. 1: 334-337.

450 Weimerskirch, H., Zotier, R., and Jouventin, P. 1989. The avifauna of the Kerguelen Islands. 451 Emu 89: 15-29.

452 Vellenga, R. 1986. Bower-building behaviour of immature satin bowerbirds Ptilonorhynchus violaceus. Aust. Field Ornithol. 11: 166-167.

454 Verheyden, C. 1988. La formation de couples hivernaux chez le Petit Bec-en-fourreau 455 (Chionis minor) et sa signification biologique. Rev. Ecol-Terre Vie 43: 375-387.

456 Winkler, D. W., S. M. Billerman and I.J. Lovette 2020. Sheathbills (Chionidae), version 1.0. In Birds of the World (S. M. Billerman, B. K. Keeney, P. G. Rodewald, and T. S. Schulenberg, Editors). Cornell Lab of Ornithology, Ithaca, NY, USA.

459 Zahavi, A. 1975. Mate selection - a selection for a handicap. J. Theor. Biol. 53: 205-214. 


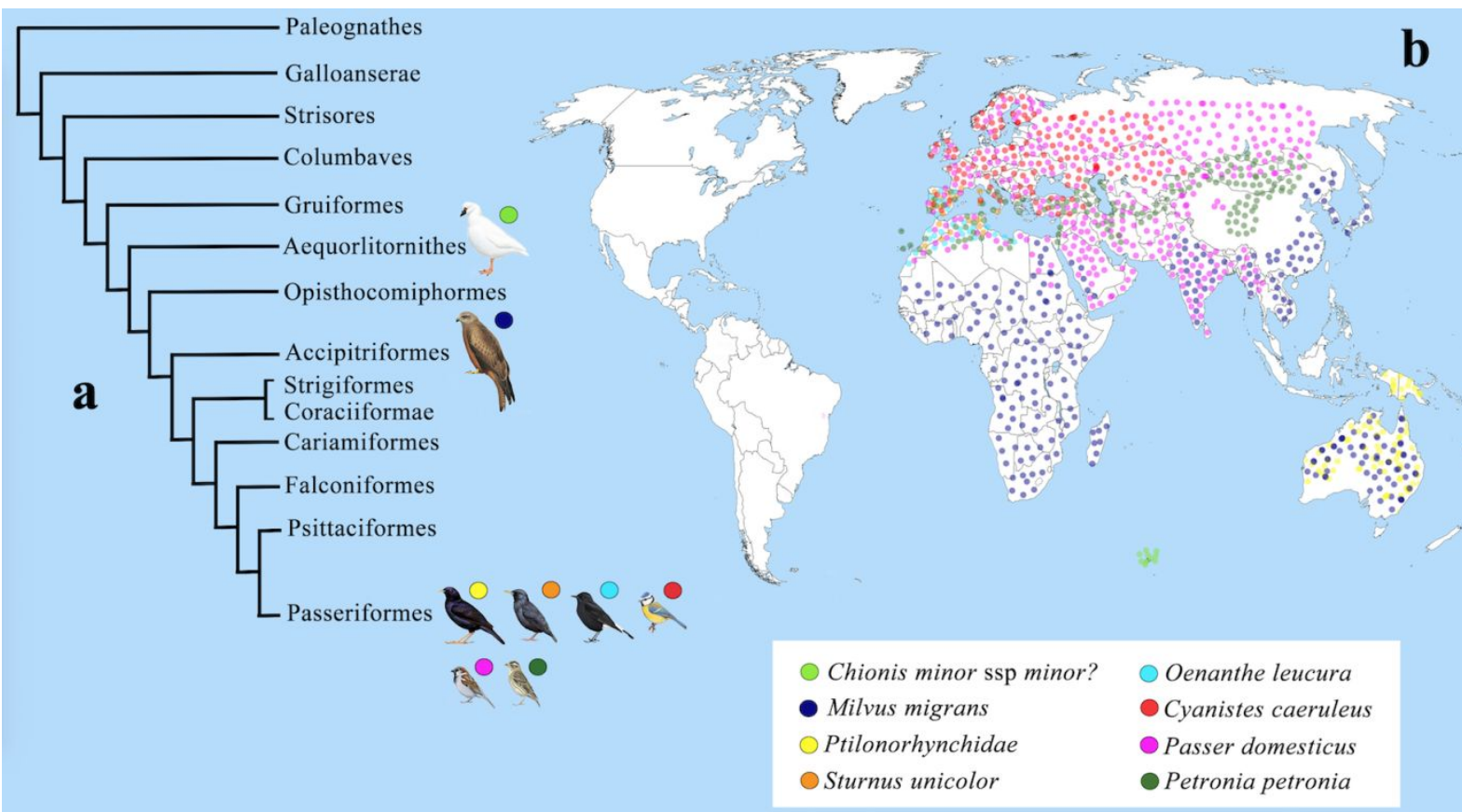

461 Figure 1. Phylogenetic and geographic distribution of avian nest-decoration behaviours for

462 communication purposes between conspecifics. a Phylogeny of birds with illustrations of 463 selected species displaying this behaviour (based on the updated phylogeny of Prum et al. 464 2015) b Worldwide distribution of avian species exhibiting nest-decoration behaviour as a 465 signal (examined experimentally in: Cyanistes caeruleus, Sanz and García-Navas, 2011; 466 Milvus migrans, Sergio et al., 2011; Oenanthe leucura, Soler et al. 1996; Passer domesticus, 467 García-Lopez de Hierro et al., 2013; Petronia petronia, García-Navas et al., 2015; 468 Ptilonorhynchidae, Borgia, 1985; Sturnus unicolor, Polo et al., 2004, Polo and Veiga, 2006). 469 Suspected nest-decoration behaviours serving a signalling function are not shown in $\mathbf{a}$ and $\mathbf{b}$ 470 (e.g. Acrocephalus arundinaceus, Trnka and Prokop, 2011; Anumbius annumbi, Delhey et al. 471 2017; Athene cunicularia, Smith and Conway, 2007; Bubo bubo, Penteriani and Delgado, 472 2008; Parotia lawesii, Pruett-Jones and Pruett-Jones, 1988; Pygoscelis antarctica, Fargallo et 473 al., 2001). Areas indicated with the coloured circles represent the species' year-round 474 distribution. 


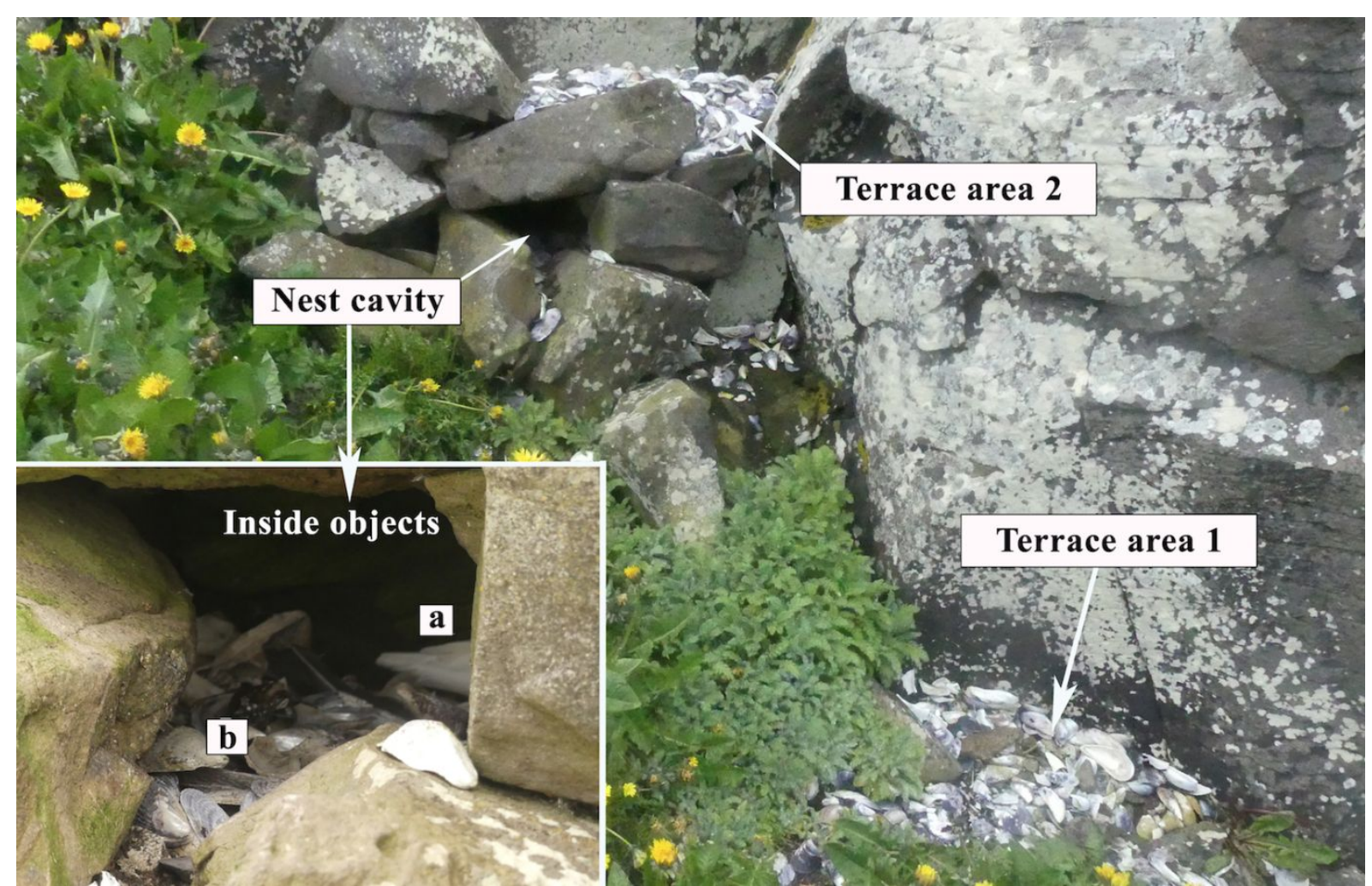

475 Figure 2. Configuration of the nest and accumulated objects at Nest 1 . Terrace areas 1

476 \& 2 contain a large number of objects, mainly Aulacomya ater mussel shells. The inset

477 magnifying the inside of the nest cavity shows an incubating bird (a) and accumulated objects

478 (b) [Photo credit: S. Danel]. 


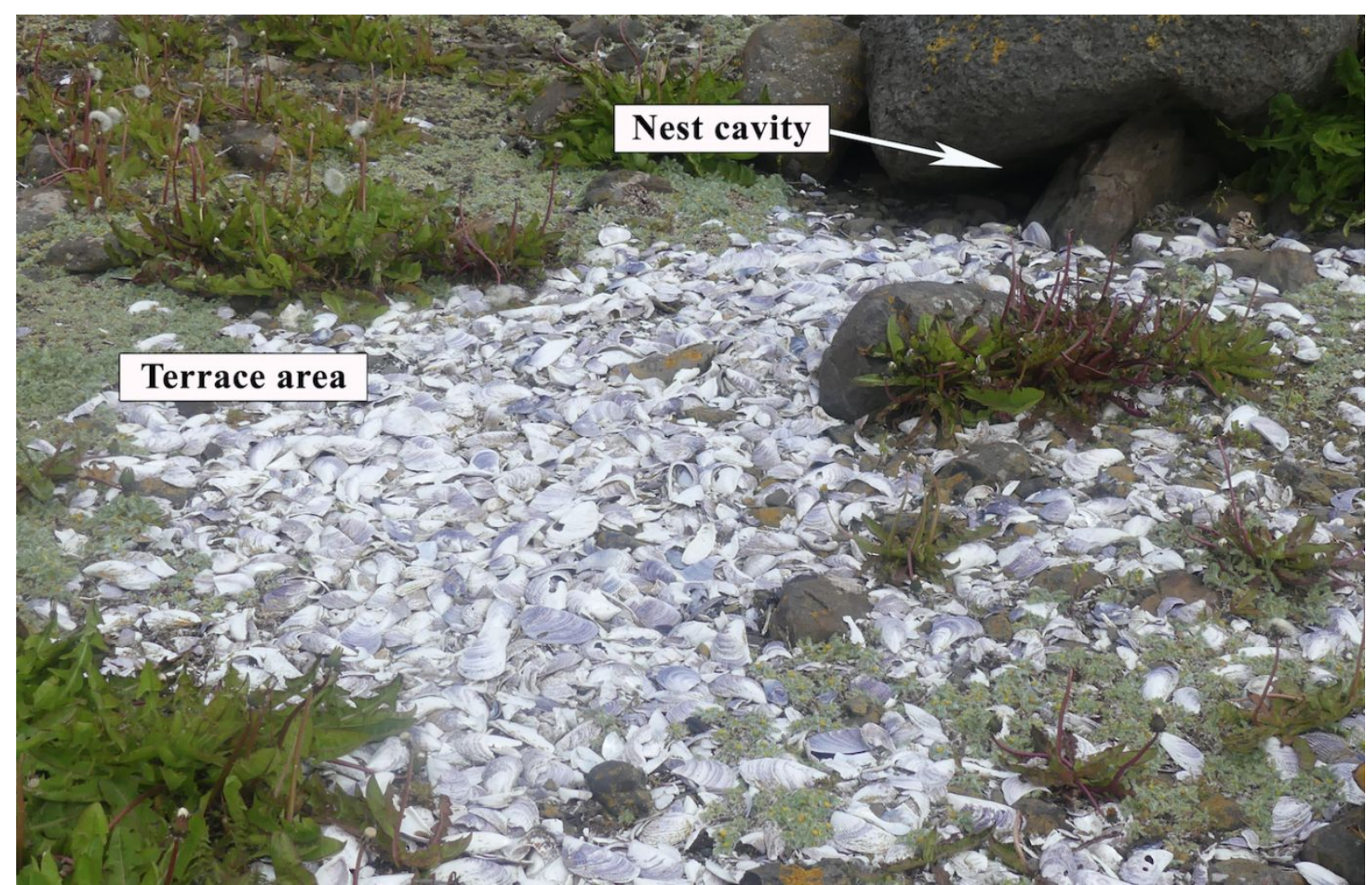

479 Figure 3. Circular terrace area at Nest 2, composed of mussel shells and limpets

480 [Photo credit: S. Danel]. 


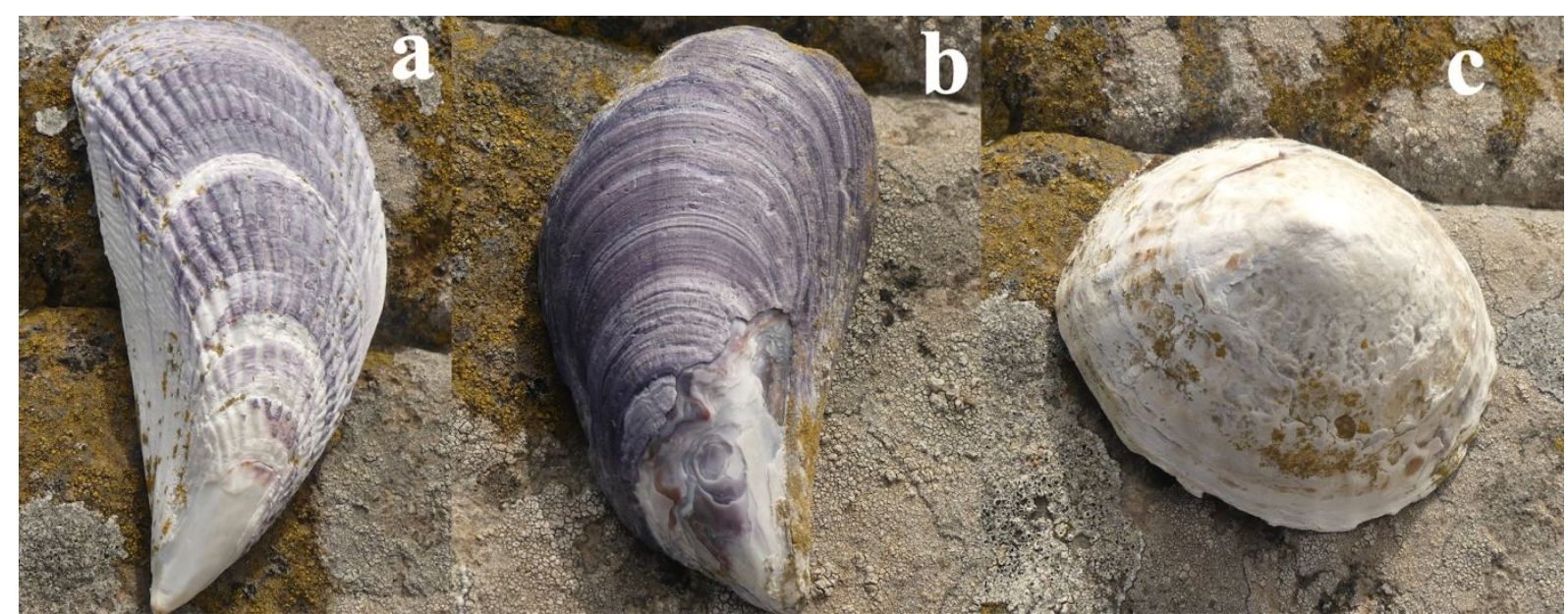

481 Figure 4. Three main types of nest-decoration objects documented at black-faced

482 sheathbill nests. $\mathbf{a}$ and $\mathbf{b}$ are marine mussel shells: ribbed mussel Aulacomya ater (a) and

483 blue mussel Mytilus desolationis (b); $\mathbf{c}$ is the limpet Nacella kerguelenensis. Birds were also

484 observed collecting and manipulating twigs (not pictured). [Photo credit: S. Danel]. 
485 Table 1. Type and number of decorative objects at each of the studied nests and reported 486 from the photographs. Decorations consist of ribbed mussels, blue mussels, and limpets 487 (twigs were not visible on the photographs). $\mathrm{TO}=$ number of shells turned over (top upside 488 down).

\begin{tabular}{lccccc}
\hline & Ribbed & Blue & Limpets & Total shells & Total TO \\
\hline Nest 1 & 159 & 5 & 2 & 166 & 3 \\
Terrace 1 & 56 & 4 & 1 & 61 & 1 \\
Terrace 2 & 215 & 9 & 3 & 227 & 4 \\
Total & & & & & 8 \\
Nest 2 & 434 & 8 & 1 & 443 & - \\
Circular & & 1 & 1 & 56 & 6 \\
Nest 3 & 54 & - & 1 & 19 & 6 \\
Terrace 1 & 18 & 1 & 2 & 75 & \\
Terrace 2 & 72 & & & & \\
Total & & & & & \\
\hline
\end{tabular}




\section{Supplemental material}

Video 1. Manipulations of nest materials (shells) outside Nest 1.

Video 2. Manipulations of nest materials (twigs) outside Nest 1.

Video 3. Manipulations of nest materials (both shells and twigs) inside Nest 1. 